\title{
Validation of the Spanish Version of Newcastle Stroke-Specific Quality of Life Measure (NEWSQOL)
}

\author{
Concepción Soto-Vidal ${ }^{1}$, Soraya Pacheco-da-Costa ${ }^{1, * \mathbb{D}}$, Victoria Calvo-Fuente ${ }^{1}$, \\ Sara Fernández-Guinea ${ }^{2}$, Carlos González-Alted ${ }^{3}$ and Tomás Gallego-Izquierdo ${ }^{1}$ \\ 1 Department of Nursing and Physiotherapy, University of Alcala, 28871 Madrid, Spain; \\ conchi.soto@uah.es (C.S.-V.); victoria.calvo@uah.es (V.C.-F.); tomas.gallego@uah.es (T.G.-I.) \\ 2 Department of Experimental Psychology, Complutense University of Madrid, 28040 Madrid, Spain; \\ sguinea@psi.ucm.es \\ 3 Medical Director State Reference Center for Brain Damage Care, 28034 Madrid, Spain; \\ cgonzaalted@imserso.es \\ * Correspondence: soraya.pacheco@uah.es
}

Received: 18 May 2020; Accepted: 11 June 2020; Published: 14 June 2020

check for updates

\begin{abstract}
Background: Stroke causes a wide variety of clinical manifestations that may have a negative impact on quality of life. Therefore, it is very important to use specific instruments for measuring quality of life in individuals who suffered a stroke. The aim of this study was to develop a psychometrically validated Spanish version of the Newcastle stroke-specific quality of life measure (NEWSQOL). Methods: A psychometric validation of the Spanish version of the NEWSQOL questionnaire was carried out in 159 patients. The reliability (intraclass correlation coefficient and Cronbach's alpha coefficient), validity (factorial analysis and Spearman's coefficient), feasibility (response rate), and the ceiling and floor effects were calculated. Results: Internal consistency showed that Cronbach's alpha coefficient was 0.93 . The test-retest reliability was high or excellent for all domains (range $0.71-0.97 p<0.001$ ). The response rate of the questionnaire was $100 \%$ and the average administration time was $20.5( \pm 7.2) \mathrm{min}$. No ceiling effect was detected and two domains (pain and vision) may have a significant potential for floor effect. Construct validity showed that all the variables are important enough to keep them all in the questionnaire. Concerning convergent construct validity, a high correlation was found with the Nottingham Health Profile, the Barthel Index, and the Modified Rankin Scale. Conclusion: The Spanish version of the NEWSQOL questionnaire is reliable, valid, and feasible to evaluate quality of life in the Spanish population.
\end{abstract}

Keywords: quality of life; stroke; validation; psychometric properties

\section{Background}

The World Health Organization defines stroke as "the rapid onset of clinical symptoms of focal or global brain dysfunction, which lasts longer than $24 \mathrm{~h}$ or leads to death, with no other apparent cause than an injury vascular" [1]. Epidemiological studies situate the worldwide incidence of stroke in about 250 cases per 100,000 inhabitants/year [2]. It is the second cause of death and one of the main reasons of disability worldwide [3,4]. In Spain, about $4 \%$ of the people over 65 years of age live with very disabling sequelae of stroke $[5,6]$. There is a wide variety of clinical manifestations, such as motor, sensory, perception and cognitive disturbances, urinary and fecal incontinence, swallowing and visual problems, pain, communication, and behavioral alterations [7-16]. These symptoms affect activities of daily life (ADL), increase the risk of falls, and have a negative impact on quality of life (QoL) [17-22]. 
It is necessary to design and assess the effectiveness of appropriate and individual therapeutic interventions, in order to understand patients' perceptions after suffering a stroke. Therefore, the aim of the interventions is not only to carry out clinical assessments, but also to evaluate the subjective patients' perceptions. As Altal pointed out, "the effects of a treatment on Stroke should be measured in terms of QoL, in addition to disability and survival" [23]. This is the real importance of studying QoL perception in stroke.

Most studies about QoL in patients who had suffered a stroke were carried out with generic QoL instruments that were used to compare different populations and diseases [24]. The inclusion of more subjective aspects started to rise at the beginning of the century, but specific instruments remain scarce and many of them do not include all the dimensions that may be affected after suffering a stroke [25].

The original Newcastle stroke-specific quality of life measure (NEWSQOL) is a specific questionnaire to measure QoL in people who suffered a stroke. Buck et al. [26] developed NEWSQOL using patient-centered methods to encompass the symptoms after a stroke. In fact, NEWSQOL is different from others questionnaires, because it includes domains about communication, cognition, and vision, and it can be used for patients with ischemic or hemorrhagic stroke, and motor aphasia. The Spanish version of the NEWSQOL was culturally adapted for the Spanish population [27], using the original questionnaire as a reference.

Since there is a lack of specific tools for assessing QoL perception after a stroke that can collect information from the patient's perspective [28], the aim of this paper was to develop a psychometrically validated Spanish version of NEWSQOL, in order to use it as a reference for assessing stroke patients' QoL in the Spanish population.

\section{Materials and Methods}

A psychometric validation of the Spanish version of NEWSQOL questionnaire was carried out between July 2011 and February 2017. The present study was approved by the Research Ethics Committee at Ramon y Cajal University Hospital in Madrid, Spain. Participants were recruited by neurologists and neurological physical therapists from 5 different reference centers in Spain: 3 hospitals (Ramon y Cajal, Principe de Asturias, and Beata Maria Ana de Jesus); Brain Damage State Centre (CEADAC); and the Institute of Neurological Diseases (IEN). All subjects who had suffered a stroke between 1 month and 2 years at the time of recruitment were included in the study by non-probabilistic sampling. The exclusion criteria was: dependency for ADL before the stroke, suffering from stroke more than once, other neurological or neuromuscular condition, moderate or severe cognitive deterioration according to Pfeiffer's questionnaire [29], psychiatric pathology previously diagnosed, neoplasia, or other serious illness with significant repercussions on QoL. After signing the written informed consent for participating in the study, all the data collected from each participant was associated with a code for anonymity guarantee. The questionnaires were administered through individualized interview with each patient.

Demographic data and clinical history of the patients was collected and those subjects who met the inclusion criteria answered the Spanish version of NEWSQOL questionnaire through an individualized interview.

NEWSQOL has 56 items in 11 domains: mobility (items 1-9); ADL/self-care (items 10-17); pain/sensation (items 18-20); vision (items 21-22); cognition (items 23-27); communication (items 28-31); feelings (items 32-37); interpersonal relationships (items 38-43); emotions (items 44-47); sleep (items 48-53); and fatigue (items 54-56). Each item is rated in range 0 to 3, and they are not significant individually. The results of each domain are obtained by the sum of the scores of the items, and higher values indicate greater impact on quality of life perception. The author of the original questionnaire does not recommend adding the scores obtained in the domains to achieve a global score [26].

Reliability was studied by test-retest reliability and internal consistency. Intraclass correlation coefficient (ICC) was performed for the test-retest reliability. It was calculated from the answers 
of the first 30 patients who came for a second interview, in a time interval between 7 and 12 days from the first interview, to answer to the questionnaire again, following the recommendations of Ramada-Rodilla et al., 2013, [30]. This time interval was selected in order to avoid complications that could arise in the follow-up of patients, such as hospital discharge, clinical problems, etc. Internal consistency was calculated by means of Cronbach's alpha $(\alpha)$, in which values greater than 0.70 show good reliability [31].

Validity was assessed by convergent construct and factorial construct. Content validity was assessed in the original questionnaire and during the process of NEWSQOL cross-cultural adaptation to Spanish [27]. In order to evaluate convergent construct validity through the correlation with the Spanish version of NEWSQOL, all participants were also administered the Nottingham Health Profile (NHP), the Barthel Index (BI), and the Modified Rankin Scale (MRS). All of them are validated in the Spanish population [32-34]. NHP is a self-administered questionnaire designed to measure a patient's view of their own health status. It consists of two parts, the first part with 38 statements belonging to six dimensions of health (energy, pain, emotional reactions, sleep, social isolation, and physical mobility), and the second contains seven areas related to ADL [32]. BI was developed to assess self-care and functional independence [33], and MRS is used for measuring the degree of disability or dependence in ADL in post-stroke patients $[34,35]$. The correlation between of the scores of the Spanish version of NEWSQOL with NHP, BI, and MRS was calculated. The statistic used was the Spearman correlation ( $\mathrm{r}$ ) for non-parametric tests. It was considered to have high validity when the correlation was between 0.30 and 0.40 [26]. For factorial construct validity, an analysis of the items was performed by the main components method, previously checking the adequacy of the sample to the factorial analysis, by means of the Bartlett Sphericity test and the measurement of the adequacy of Kaiser-Meyer-Olkin (KMO coefficient).

Feasibility was evaluated by percentage of individual items that were not answered, the percentage of patients who did not answer any items, and the average time required to fulfill the questionnaire. Ceiling and floor effects were analyzed to measure the percentage of patients with the best and worst possible score obtained. Ceiling or floor effects are considered when more than $20 \%$ of the responses get the best or worst possible score respectively [26].

IBM (SPSS Statistics, Armonk, New York, USA) was used for the statistical analysis of the data obtained, a $p$-value of $<0.05$ was considered statistically significant for all evaluations.

\section{Results}

A total of 168 subjects were recruited for the study ( 3 per each questionnaire item); 9 did not accept to participate. Table 1 shows the socio-demographic and clinical characteristics of the 159 subjects who participated in this study. Most of the subjects were middle-aged (52 years old) men (56.6\%) who were under sick leave (65.4\%) and had help from their families (89.3\%).

Results concerning reliability (test-retest reproducibility and internal consistency), and feasibility (floor/ceiling effects) are shown in Table 2. The Spanish version of the NEWSQOL questionnaire showed high internal consistency, with a Cronbach's $\alpha$ coefficient of 0.93 (considering good reliability of values greater than 0.70 ), and a range between 0.57 and 0.96 for the domains. Intraclass correlation coefficient (ICC) showed good to excellent reproducibility test-retest for all domains (0.70-0.97), considering good values higher than 0.75 . All values were statistically significant $(p<0.001)$. There were no ceiling effects, although floor effects were found for the domains pain, vision, interpersonal relationships, and fatigue. The rate of the fulfilling of the questionnaire was $100 \%$, and the average time was $20.5( \pm 7.2) \mathrm{min}$.

Regarding the factorial construct validity, Table 3 shows the values obtained in the Bartlett sphericity test and the Kaiser-Meyer-Olkin adaptation measure (KMO). The analysis of the main components of the questionnaire indicated that 14 components explain $73.96 \%$ of the variance. This fact shows that all items contribute, at least, in one of the domains. 
Table 1. Socio-demographics and clinical characteristics of the sample.

\begin{tabular}{lc}
\hline \multicolumn{2}{c}{ Baseline Characteristics of the Sample } \\
\hline Sex (\%) & \\
Women & 43.4 \\
Men & 56.6 \\
Age [Mean (SD)] & $52.09( \pm 15.72)$ \\
Type of Stroke (\%) & 55.3 \\
Ischemic & 44.7 \\
Hemorrhagic & \\
Hemibody affected (\%) & 47.2 \\
Left & 45.3 \\
Right & 7.5 \\
Both & $7.58( \pm 5.72)$ \\
Time after stroke [Mean (SD)] & \\
Employment Situation (\%) & 0 \\
Active & 7.5 \\
Unemployed & 26.4 \\
Retired & 65.4 \\
Sick leave & \\
Family situation & 89.3 \\
Family help & 1.3 \\
Lives alone & 8.8 \\
Institutionalized &
\end{tabular}

Table 2. Values of internal consistency, test-retest reliability, ceiling, and floor effect.

\begin{tabular}{cccc}
\hline \multirow{2}{*}{ NEWSQOL Dimensions } & Internal Consistency & Test-Retest & \multicolumn{2}{c}{ Ceiling/Floor Effect } \\
\cline { 2 - 4 } & $(\boldsymbol{n}=\mathbf{1 5 9 )}$ & $\mathbf{( n = 3 0 )}$ \\
\hline Cronbach's $\alpha$ & ICC & $(\%)$ \\
\hline NEWSQOL & 0.94 & & \\
Mobility & 0.96 & 0.96 & $16 / 3$ \\
ADL/self-care & 0.92 & 0.97 & $22 / 3$ \\
Pain /sensation & 0.68 & 0.70 & $2 / 62$ \\
Vision & 0.79 & 0.83 & $5 / 45$ \\
Cognition & 0.86 & 0.84 & $6 / 9$ \\
Communication & 0.88 & 0.95 & $18 / 13$ \\
Feelings & 0.78 & 0.87 & $4 / 0$ \\
Interpersonal Relationship & 0.79 & 0.88 & $0 / 35$ \\
Emotion & 0.57 & 0.73 & $2 / 0$ \\
Sleep & 0.78 & 0.73 & $1 / 3$ \\
Fatigue & 0.66 & 0.80 & $6 / 38$ \\
\hline
\end{tabular}

ICC: intraclass correlation coefficient; ADL: activities of the daily life.

Table 4 shows high convergent construct validity values and all domains of the Spanish version of the NEWSQOL had a positive correlation with NHP and MRS scores, which shows that the higher the functionality, the higher the QoL. The higher Spearman coefficient of NHP was related to mobility domains, $\mathrm{r}=0.688(p<0.01)$. The Spearman coefficient of MRS was high in mobility domain $\mathrm{r}=0.871$ $(p<0.01)$, ADL $r=0.770(p<0.01)$, and feelings $r=0.469(p<0.01)$. It was also moderate to pain domains $r=0.244(p<0.01)$, cognition $r=0.207(p<0.01)$, interpersonal relations $r=0.305(p<0.01)$, communication $\mathrm{r}=0.240(p<0.01)$, vision $\mathrm{r}=0.186(p<0.01)$, and fatigue $\mathrm{r}=0.218(p<0.01)$.

The Spanish version of the NEWSQOL had a negative correlation with the BI. Spearman coefficient was high for the domains of mobility $\mathrm{r}=-0.883(p<0.01)$, limitation for ALD $\mathrm{r}=-0.808(p<0.01)$, and it was moderate for domains of feelings $r=-0.382(p<0.01)$, interpersonal relations $r=-0.251$ $(p<0.01)$, communication $\mathrm{r}=-0.277(p<0.01)$, cognition $\mathrm{r}=-0.184(p<0.01)$, and vision $\mathrm{r}=-0.197$ 
$(p<0.01)$. The Spearman coefficient was low to pain $\mathrm{r}=-0.146(p<0.05)$ and fatigue $\mathrm{r}=-0.151$ $(p<0.05)$ (Table 5).

Table 3. Values of factorial construct validity of the Newcastle stroke-specific quality of life measure (NEWSQOL).

\begin{tabular}{ccccc}
\hline NEWSQOL Dimensions & Bartlett & KMO & Number of Items & Total Variance \% \\
\hline NEWSQOL & 0.000 & 0.809 & 56 & 73.96 \\
Mobility & 0.000 & 0.933 & 9 & 70.98 \\
ADL/self-care & 0.000 & 0.885 & 8 & 79.20 \\
Pain /sensation & 0.000 & 0.508 & 3 & 61.32 \\
Vision & 0.000 & 0.500 & 2 & 81.38 \\
Cognition & 0.000 & 0.686 & 5 & 63.65 \\
Communication & 0.000 & 0.801 & 4 & 72.97 \\
Feelings & 0.000 & 0.712 & 8 & 56.80 \\
Interpersonal relationships & 0.000 & 0.766 & 6 & 52.32 \\
Emotion & 0.000 & 0.607 & 4 & 43.92 \\
Sleep & 0.000 & 0.698 & 6 & 85.20 \\
Fatigue & 0.000 & 0.559 & 3 & 57.52 \\
\hline
\end{tabular}

KMO: Kaiser-Meyer-Olkin; ADL: activities of daily life.

Table 4. Values of convergent construct validity (Spearman's coefficient) of the NEWSQOL, Nottingham Health Profile, and Modified Rankin Scale.

\begin{tabular}{cccccccc}
\hline \multirow{2}{*}{ NEWSQOL } & \multicolumn{9}{c}{ NHP } \\
\cline { 2 - 7 } & PM & Pain & Sleep & Energy & ER & SI \\
\hline Mobility & $0.688^{* *}$ & 0.098 & $0.308^{* *}$ & $0.192^{* *}$ & $0.304^{* *}$ & $0.343^{* *}$ & $0.871^{* *}$ \\
ADL/self-care & $0.615^{* *}$ & 0.104 & $0.233^{* *}$ & $0.179^{*}$ & $0.336^{* *}$ & $0.280^{* *}$ & $0.770^{* *}$ \\
Pain /sensation & $0.337^{* *}$ & $0.722^{* *}$ & $0.355^{* *}$ & $0.280^{* *}$ & $0.136^{*}$ & $0.283^{* *}$ & $0.244^{* *}$ \\
Vision & $0.297^{* *}$ & 0.093 & 0.123 & 0.104 & $0.198^{* *}$ & $0.150^{*}$ & $0.186^{* *}$ \\
Cognition & $0.262^{* *}$ & $0.218^{* *}$ & 0.044 & $0.228^{* *}$ & $0.276^{* *}$ & $0.319^{* *}$ & $0.207^{* *}$ \\
Communication & $0.166^{*}$ & -0.028 & -0.014 & -0.004 & $0.288^{* *}$ & $0.113^{* *}$ & $0.240^{* *}$ \\
Feelings & $0.311^{* *}$ & $0.217^{*}$ & $0.311^{* *}$ & $0.343^{* *}$ & $0.470^{* *}$ & $0.615^{* *}$ & $0.469^{* *}$ \\
Interpersonal relationships & $0.333^{* *}$ & $0.200^{* *}$ & $0.246^{* *}$ & $0.313^{* *}$ & $0.515^{* *}$ & $0.644^{* *}$ & $0.305^{* *}$ \\
Emotion & $0.239^{* *}$ & $0.066^{*}$ & 0.206 & $0.497^{* *}$ & $0.494^{* *}$ & $0.484^{* *}$ & 0.255 \\
Sleep & 0.239 & 0.066 & 0.206 & $0.497^{* *}$ & $0.494^{* *}$ & $0.484^{* *}$ & -0.041 \\
Fatigue & $0.272^{* *}$ & $0.162^{*}$ & 0.083 & $0.535^{* *}$ & $0.256^{* *}$ & $0.422^{* *}$ & $0.218^{* *}$ \\
\hline
\end{tabular}

NHP: Nottingham Health Profile; MRS: Modified Rankin Scale; PM: Physical mobility; ER: Emotional Reactions; SI: Social Isolation; ADL: activities of daily life; ${ }^{*} p \leq 0.05 ;{ }^{* *} p \leq 0.01$.

Table 5. Values of Convergent construct analysis (Spearman's coefficient) of the NEWSQOL and Barthel Index.

\begin{tabular}{cccccccccccc}
\hline Newsqol & Barthel Index & Feeding & Bathing & Grooming & Dressing & Boewls & Bladder & Toilt Use & Transfers & Mobility & Stairs \\
\hline Mobility & $-0.883^{* *}$ & $-0.520^{* *}$ & $-0.726^{* *}$ & $-0.774^{* *}$ & $-0.414^{* *}$ & $-0.377^{* *}$ & $-0.301^{* *}$ & $-0.786^{* *}$ & $-0.839^{* *}$ & $-0.868^{* *}$ & $-0.871^{* *}$ \\
ADL/self-care & $-0.808^{* *}$ & $-0.566^{* *}$ & $-0.679^{* *}$ & $-0.802^{* *}$ & $-0.367^{* *}$ & $-0.254^{* *}$ & $-0.199^{* *}$ & $-0.711^{* *}$ & $-0.777^{* *}$ & $-0.755^{* *}$ & $-0.747^{* *}$ \\
Pain /sensation & $-0.146^{*}$ & $-0.161^{*}$ & -0.077 & -0.079 & $-0.212^{* *}$ & $-0.198^{* *}$ & -0.086 & $-0.085^{*}$ & -0.103 & $-0.138^{*}$ & -0.097 \\
Vision & $-0.197^{* *}$ & 0.000 & -0.091 & $-0.170^{*}$ & $-0.305^{* *}$ & $-0.246^{* *}$ & -0.124 & $-0.204^{* *}$ & $-0.228^{* *}$ & $-0.191^{* *}$ & $-0.197^{* *}$ \\
Cognition & $-0.184^{*}$ & -0.123 & -0.094 & -0.112 & $-0.145^{*}$ & $-0.210^{* *}$ & $-0.187^{* *}$ & $-0.156^{*}$ & $-0.164^{*}$ & $-0.153^{*}$ & $-0.164^{*}$ \\
Communication & $-0.277^{* *}$ & $-0.154^{*}$ & $-0.159^{*}$ & $-0.170^{*}$ & $-0.310^{* *}$ & $-0.204^{* *}$ & $-0.166^{*}$ & $-0.199^{* *}$ & $-0.306^{* *}$ & $-0.212^{* *}$ & $-0.265^{* *}$ \\
Feelings & $-0.382^{* *}$ & $-0.224^{* *}$ & $-0.380^{* *}$ & $-0.387^{* *}$ & $-0.163^{*}$ & -0.095 & $-0.152^{*}$ & $-0.343^{* *}$ & $-0.392^{* *}$ & $-0.311^{* *}$ & $-0.369^{* *}$ \\
IR & $-0.251^{* *}$ & -0.051 & $-0.300^{* *}$ & $-0.216^{* *}$ & $-0.137^{*}$ & -0.011 & -0.078 & $-0.146^{*}$ & $-0.216^{* *}$ & $-0.216^{* *}$ & $-0.279^{* *}$ \\
Emotion & $-0.322^{*}$ & -0.162 & -0.256 & $-0.459^{* *}$ & -0.084 & 0.029 & -0.060 & $-0.342^{*}$ & $-0.381^{*}$ & -0.304 & -0.155 \\
Sleep & -0.170 & -0.151 & -0.033 & -0.128 & -0.154 & -0.264 & $-0.503^{* *}$ & -0.135 & -0.111 & -0.043 & -0.050 \\
Fatigue & -0.151 & -0.057 & -0.107 & $-0.179^{*}$ & -0.099 & $-0.133^{*}$ & $-0.134^{*}$ & $-0.210^{* *}$ & $-0.141^{*}$ & -0.116 & $-0.151^{*}$ \\
\hline
\end{tabular}

ADL: activities of daily life; IR: Interpersonal relationships; ${ }^{*} p \leq 0.05 ;{ }^{* *} p \leq 0.01$.

\section{Discussion}

As far as the authors know, this is the first validation study for the NEWSQOL questionnaire in another language than English, since no other cross-culturally adaptations nor validations were found in the literature.

In the recent years, various countries have been using this instrument for measuring quality of life $[10,20]$. The perception of the patients' perspective about their illness allows the knowledge of 
the clinical decision on the best intervention for patients with a chronic disease, in order to improve their quality of life $[36,37]$. The NEWSQOL is a recommended measure to assess QoL for many reasons. First of all, because it was developed following patient-centered methods and it includes all the relevant aspects, from patients' point of view and perspective, which may be present after a stroke. Besides, it can be administered to patients who suffered either hemorrhagic or ischemic stroke, since the clinical manifestations are similar $[7-9,19]$. The present study followed the original questionnaire methodology.

The lack of cultural adaptation of the instrument in other countries made it the impossible to use other studies' sample size as reference. In the literature, the studies about psychometric validation of specific questionnaires for stroke showed a wide variability of sample size [38-43]. In the present study, the authors decided to recruit three patients for each item of the original questionnaire, following Argimon's methodology [44], which states that a questionnaire has to have a sample of between 2 and 10 subjects per questionnaire item. The sample size was larger than other validation studies of specific questionnaires for stroke [45] and it is similar to other studies of patients with stroke, regarding age, type of stroke, hemibody affected, comorbidity, and family situation $[2,5,7,8,11-15,21,46]$. The patients were recruited from different reference centers that receive patients from all over Spain, because they have the most innovative treatments to address stroke, which could ensure a wider geographical distribution of the sample.

Unlike other specific instruments for measuring QoL after a stroke, the NEWSQoL includes the dimensions of communication, cognition, and vision, which are relevant aspects for stroke survivors. The instrument can also be used for both, ischemic and hemorrhagic strokes, and for patients with motor aphasia.

The results found in the study were very satisfactory. As for viability, the high level of response $(100 \%)$ may have been influenced by administering the questionnaire through personal and individualized interviews. The data of effect ceiling and ground coincide with those provided by the original questionnaire [26] showing that there is no ceiling effect in any domain, but floor effects were found for the domains pain, vision, interpersonal relations, and fatigue. The time for its completion also coincide.

Regarding reliability, the questionnaire as a whole showed excellent results on internal consistency. When the domains were analyzed independently, there were also excellent or very good correlations, except for the domains of emotions and pain, which showed moderate internal consistency. Test-retest reliability showed good or excellent correlation for all domains. These results coincide with those provided by the original questionnaire and the Spanish cultural adaptation study [27].

Construct validation highlighted that all variables have enough importance, so that they all must be in the questionnaire, due to their contribution to one of the 11 dimensions. Factorial analysis supported its one-dimensionality, as in the original questionnaire [26].

The results of the convergent construct validity indicated high correlation between the domains that measure the same aspects. It seems logical that a mobility deficit involves greater difficulty in performing ADL and may have an impact on sleeping, social isolation, and emotional reactions, but it does not necessarily involve increased pain [13]. The pain correlated with physical mobility, and may affect sleep, energy, and emotional reactions. The domain of vision showed moderate correlation with physical mobility and social isolation, which may be reduced by visual deficit [19,47]. Memory and concentration showed correlation with physical mobility, pain, energy, physical isolation, and emotional reactions $[8,9]$. Communication had a correlation with social isolation $[16,48]$, and feelings showed correlation with social isolation and emotional reactions [49]. Fatigue showed correlation with energy, emotional reactions, physical mobility, and social isolation similar to the original questionnaire [26].

Correlations with MRS emphasize the idea of not associating disability only to physical limitation, but also to social activity, interpersonal relations, cognition, vision, and communication, aspects that may lead to the perception of disability [50]. Regarding the BI, there was no correlation with sleep and emotion. 


\section{Conclusions}

The Spanish version of the NEWSQOL questionnaire is reliable, valid, and feasible for assessing QoL after a stroke in the Spanish population. Consequently, this questionnaire may be useful in Spanish-speaking populations and for making cross-ethnic and cross-cultural comparisons with other English-speaking countries that have a large Spanish-speaking population. Besides, as this is the first validation study for the NEWSQOL in another language, it may be a reference frame for other cross-culturally adaptations and validations in other countries.

Author Contributions: Conceptualization, T.G.-I.; methodology, C.S.-V., S.P.-d.-C., V.C.-F., S.F.-G., C.G.-A.; validation, C.S.-V.; formal analysis, T.G.-I.; investigation, C.S.-V., S.P.-d.-C., V.C.-F., S.F.-G.; resources, C.S.-V; data curation, C.G.-A., T.G.-I.; writing-original draft preparation, C.S.-V.; writing-review and editing, S.P.-d.-C.; supervision, V.C.-F.; project administration, C.S.-V., S.P.-d.-C. All authors have read and agreed to the published version of the manuscript.

Funding: This research received no external funding.

Conflicts of Interest: The authors declare no conflict of interest.

\section{References}

1. Azevedo-da-Costa, F.; Araujo-da-Silva, D.; da Rocha, V. Condición funcional de los pacientes tras un accidente vascular encefálico. Rev. Neurol. 2006, 42, 591-595. [CrossRef] [PubMed]

2. Béjot, Y.; Daubail, B.; Giroud, M. Epidemiology of stroke and transit ischemic attacks: Current knowloge and perspectives. Revue Neurol. 2016, 172, 59-68. [CrossRef] [PubMed]

3. Balakrishnan, R.; Kaplan, B.; Negron, R.; Fei, K.; Goldfinger, J.Z.; Horowitz, C.R. Life after Stroke in an Urban Minority Population: A Photovoice Project. Int. J. Environ. Res. Public Health 2017, 14, 293. [CrossRef] [PubMed]

4. Katan, M.; Luft, A. Global Burden of Stroke. Semin. Neurol. 2018, 38, 208-211. [CrossRef] [PubMed]

5. Brea, A.; Laclaustra, M.; Martorell, E.; Pedragosa, A. Epidemiology of cerebrovascular disease in Spain. Clin. Investig. Arterioscler. 2013, 25, 211-217. [PubMed]

6. Arboix, A.; Massons, J.; García-Eroles, L.; Oliveres, M. Stroke in young adults: Incidence and clinical picture in 280 patients according to their aetiological subtype. Med. Clin. 2016, 146, 207-211. [CrossRef] [PubMed]

7. Kessner, S.S.; Bingel, U.; Thomalla, G. Somatosensory deficits after stroke: A scoping review. Top. Stroke Rehabil. 2016, 23, 136-146. [CrossRef]

8. Moran, G.M.; Fletcher, B.; Feltham, M.G.; Calvert, M.; Sackley, C.; Marshall, T. Fatigue, psychological and cognitive impairment following transient ischaemic attack and minor stroke: A systematic review. Eur. J. Neurol. 2014, 21, 1258-1267. [CrossRef]

9. Pinter, D.; Enzinger, C.; Gattringer, T.; Eppinger, S.; Niederkorn, K.; Horner, S.; Fandler, S.; Kneihsl, M.; Krenn, K.; Bachmaier, G.; et al. Prevalence and short-term changes of cognitive dysfunction in young ischaemic stroke patients. Eur. J. Neurol. 2019, 26, 727-732. [CrossRef]

10. Baumann, M.; Couffignal, S.; Le Bihan, E.; Chau, N. Life satisfaction two-years after stroke onset: The effects of gender, sex occupational status, memory function and quality of life among stroke patients (NewsQol) and their family caregivers (WhoQol-bref) in Luxembourg. BMC Neurol. 2012, 25, 105. [CrossRef]

11. Hepworth, L.R.; Rowe, F.J.; Harper, R.; Jarvis, K.; Shipman, T.; Rodgers, H. Patient reported outcome measures for visual impairment after stroke: A systematic review. Health Qual. Life Outcomes 2015, 15, 146. [CrossRef] [PubMed]

12. Dai, C.; Liu, W.; Chen, S.; Yang, C.; Tung, Y.; Chou, L.; Lin, L.-C. Anosognosia, neglect and quality of life of right hemisphere stroke survivors. Eur. J. Neurol. 2014, 21, 797-801. [CrossRef] [PubMed]

13. Dorňák, T.; Justanová, M.; Konvalinková, R.; Říha, M.; Mužík, J.; Hoskovcová, M.; Navrátilová, D.; Otruba, p.; Gál, O.; Svobodová, I. Prevalence and evolution of spasticity in patients suffering from first-ever stroke with carotid origin: A prospective, longitudinal study. Eur. J. Neurol. 2019, 26, 880-886. [CrossRef] [PubMed]

14. Feyissa, A.M.; Hasan, T.F.; Meschia, J.F. Stroke-related epilepsy. Eur. J. Neurol. 2019, 26, 18-e3. [CrossRef] [PubMed]

15. Espárrago Llorca, G.; Castilla-Guerra, L.; Fernández Moreno, M.C.; Ruiz Doblado, S.; Jiménez Hernández, M.D. Post-stroke depression: An update. Rev. Neurol. 2015, 30, 23-31. [CrossRef] 
16. Lima, R.R.; Rose, M.L.; Lima, H.N.; Cabral, N.L.; Silveira, N.C.; Massi, G.A. Prevalence of aphasia after stroke in a hospital population in southern Brazil: A retrospective cohort study. Top. Stroke Rehabil. 2019, 27, 1-9. [CrossRef]

17. Haacke, C.; Althaus, A.; Spottke, A.; Siebert, U.; Back, T.; Dodel, R. Long-term outcome after stroke: Evaluating health-related quality of life using utility measurements. Stroke 2006, 37, 193-198. [CrossRef]

18. Carod-Artal, F.J. Determining quality of life in stroke survivors. Expert Rev. Pharmacoecon. Outcomes Res. 2012, 12, 199-211. [CrossRef]

19. Sand, K.M.; Wilhelmsen, G.; Naess, H.; Midelfart, A.; Thomassen, L.; Hoff, J.M. Vision problems in ischaemic stroke patients: Effects on life quality and disability. Eur. J. Neurol. 2016, 23, 1-7. [CrossRef]

20. Heikinheimo, T.; Chimbayo, D. Quality of life after first-ever stroke: An interview-based study from Blantyre, Malawi. Malawi Med. J. 2015, 27, 50-54. [CrossRef]

21. Arba, F.; Ali, M.; Quinn, T.J.; Hankey, G.J.; Lees, K.R.; Inzitari, D. Lacunar Infarcts, Depression, and Anxiety Symptoms One Year after Stroke. J. Stroke Cerebrovasc. Dis. 2016, 25, 831-834. [CrossRef] [PubMed]

22. Katona, M.; Schmidt, R.; Schupp, W.; Graessel, E. Predictors of health-related quality of life in stroke patients after neurological inpatient rehabilitation: A prospective study. Health Qual. Life Outcomes 2015, 13, 58. [CrossRef] [PubMed]

23. Carod-Artal, F.J. Escalas específicas para la evaluación de la calidad de vida en el ictus. Rev. Neurol. 2004, 39, 1052-1062. [PubMed]

24. Carod-Artal, F.J. Measurement of the quality of life in stroke survivors. Rev. Neurol. 1999, 29, 447-456.

25. Golomb, B.A.; Vickrey, B.G.; Hays, R.D. A review of health-related quality-of-life measures in stroke. Pharmacoeconomics 2001, 19, 155-185. [CrossRef]

26. Buck, D.; Jacoby, A.; Massey, A.; Steen, N.; Sharma, A.; Ford, G.A. Development and validation of NEWSQOL, the Newcastle Stroke-Specific Quality of Life Measure. Cerebrovasc. Dis. 2004, 17, 143-152. [CrossRef]

27. Soto-Vidal, C.; Pacheco-da-Costa, S.; Fernandez-Guinea, S.; Gallego-Izquierdo, T. Translation into Spanish and a preliminary analysis of the psychometric properties of the Newcastle Stroke-Specific Quality of Life Measure (NEWSQOL) questionnaire for rating the quality of life among post-stroke patients. Rev. Neurol. 2017, 65, 481-488.

28. Price-Haywood, E.G.; Harden-Barrios, J.; Carr, C.; Reddy, L.; Bazzano, L.A.; van Driel, M.L. Patient-reported outcomes in stroke clinical trials 2002-2016: A systematic review. Qual. Life Res. 2019, 28, 1119-1128. [CrossRef]

29. De la Iglesia, J.; Herrero, R.; Vilches, M.; Taberné, C.; Colomer, C.; Luque, R. Adaptación y validación al castellano del cuestionario de Pfeiffer (SPMSQ) para detectar la existencia de deterioro cognitivo en personas mayores de 65 años. Med. Clin. 2001, 117, 129-134. [CrossRef]

30. Ramada-Rodilla, J.; Serra-Pujadas, C.; Delclós-Clanchet, G.L. Cross-cultural adaptation and health questionnaires validation: Revision and methodological recommendations. Salud Pública Mex. 2013, 55, 57-66. [CrossRef]

31. Carvajal, A.; Centeno, C.; Watson, R.; Martínez, M.; Sanz Rubiales, Á. ¿Cómo validar un instrumento de medida de la salud? An. Sist. Sanit. Navar. 2011, 34, 63-72. [CrossRef] [PubMed]

32. Alonso, J.; Anto, J.; Moreno, C. Spanish version of the Nottingham Health Profile: Translation and preliminary validity. Am. J. Public Health 1990, 80, 704-708. [CrossRef] [PubMed]

33. Bernaola-Sagardui, I. Validación del índice de Barthel en la población española. Enferm. Clín. 2018, 28, 210-211. [CrossRef] [PubMed]

34. Quinn, T.J.; Dawson, J.; Walters, M.R.; Lees, K.R. Reliability of the modified Rankin Scale: A systematic review. Stroke 2009, 40, 3393-3395. [CrossRef]

35. Broderick, J.P.; Adeoye, O.; Elm, J. Evolution of the Modified Rankin Scale and Its Use in Future Stroke Trials. Stroke 2017, 48, 2007-2012. [CrossRef]

36. Kimman, M.L.; Wijsenbeek, M.S.; van Kuijk, S.M.; Wijnsma, K.L.; van de Kar, N.C.A.J.; Storm, M.; van Jaarsveld, X.; Dirksem, C.D. PESaM Collaborating Group. Validity of the Patient Experiences and Satisfaction with Medications (PESaM) Questionnaire. Patient Patient Cent. Outcomes Res. 2019, 12, 149-162. [CrossRef]

37. Orozco-Beltrán, D.; de Toro, J.; Galindo, M.J.; Marín-Jiménez, I.; Casellas, F.; Fuster-RuizdeApodaca, M.J.; García-Vivar, M.L.; Hormigo-Pozo, A.; Guilabert, M.; Sánchez-Vega, N.; et al. Healthcare experience and their relationship with demographic, disease and healthcare-related variables: A cross-sectional survey of 
patients with chronic diseases using the IEXPAC scale. Patient Patient Cent. Outcomes Res. 2019, 12, 307-317. [CrossRef]

38. Fernandez-Concepcion, O.; Ramirez-Perez, E.; Alvarez, M.; Buergo-Zuaznabar, M. Validation of the stroke-specific quality of life scale (ECVI-38). Rev. Neurol. 2008, 46, 147-152.

39. Fernandez-Concepcion, O.; Roman-Pastoriza, Y.; Alvarez-Gonzalez, M.; Verdecia-Fraga, R.; Ramirez-Perez, E.; Martinez-Gonzalez-Quevedo, J.; Buergo-Zuaznábar, M.A. The development of a scale to evaluate the quality of life in stroke survivors. Rev. Neurol. 2004, 39, 915-923.

40. Carod-Artal, F.J.; González-Gutiérrez, J.; Egido-Herrero, J.A.; Varela de Seijas, E. Propiedades métricas de la versión española del perfil de las consecuencias de la enfermedad de 30 ítems adaptado al ictus (SIP30-AI). Rev. Neurol. 2007, 45, 647-654. [CrossRef]

41. Muus, I.; Williams, L.; Ringsberg, K. Validation of the Stroke Specific Quality of Life Scale (SS-QOL): Test of reliability and validity of the Danish version (SS-QOL-DK). Clin. Rehabil. 2007, 21, 620-627. [CrossRef] [PubMed]

42. Lima, R.; Teixeira-Salmela, L.; Magalhães, L.; Gomes-Neto, M. Propriedades psicométricas da versão brasileira da escala de qualidade de vida específica para acidente vascular encefálico: Aplicação do modelo Rasch. Rev. Bras. Fisioter. 2008, 12, 149-156. [CrossRef]

43. Streiner, D.; Norman, G.; Fulton, C. Health measurement scales: A practical guide to their development and use. Int. J. Rehab. Res. 1991, 14, 364. [CrossRef]

44. Argimon, J.; Jiménez, J. Métodos de Investigación Clínica y Epidemiológica; Elsevier: Madrid, Spain, 2004.

45. Cabanas-Valdes, R.; Girabent-Farres, M.; Canovas-Verge, D.; Caballero-Gomez, F.M.; German-Romero, A.; Bagur-Calafat, C. Spanish translation and validation of the Postural Assessment Scale for Stroke Patients (PASS) to assess balance and postural control in adult post-stroke patients. Rev. Neurol. 2015, 60, 151-158. [PubMed]

46. Vu, H.M.; Nguyen, L.H.; Tran, T.H.; Pham, K.T.H.; Phan, H.T.; Nguyen, H.N.; Tran, B.X.; Latkin, C.A.; Ho, C.S.H.; Ho, R.C.M. Effects of Chronic Comorbidities on the Health-Related Quality of Life among Older Patients after Falls in Vietnamese Hospitals. Int. J. Environ. Res. Public Health 2019, 16, 3623. [CrossRef]

47. Tramontano, M.; Dell'Uomo, D.; Cinnera, A.M.; Luciani, C.; Di Lorenzo, C.; Marcotulli, M.; Vona, F.; Mercuro, A.; Abbruzzese, S. Visual-spatial training in patients with sub-acute stroke without neglect: A randomized, single-blind controlled trial. Funct. Neurol. 2019, 34, 7-13. [PubMed]

48. Northcott, S.; Hilari, K. Why do people lose their friends after a stroke? Int. J. Lang. Commun. Disord. 2011, 46, 524-534. [CrossRef]

49. McAleese, N.; Guzman, A.; O’Rourke, S.J.; Gillespie, D.C. Post-stroke emotionalism: A qualitative investigation. Disabil. Rehabil. 2019, 1-9. [CrossRef]

50. Koleck, M.; Gana, K.; Lucot, C.; Darrigrand, B.; Mazaux, J.; Glize, B. Quality of life in aphasic patients 1 year after a first stroke. Qual. Life Res. 2017, 26, 45-54. [CrossRef] 